\title{
Efficiency comparison between hydrogen and gasoline, on a bi-fuel hydrogen/gasoline engine
}

S. Verhelst*, P. Maesschalck, N. Rombaut and R. Sierens

Department of Flow, Heat and Combustion Mechanics

Ghent University

Sint-Pietersnieuwstraat 41, B-9000 Gent, Belgium

*corresponding author: T +32 9264 3306; F +32 9264 3590; E-mail Sebastian.Verhelst@,UGent.be

\begin{abstract}
The combustion characteristics of hydrogen compared to gasoline offer the potential of an increased engine efficiency, especially at part load. Here, results are presented of the brake thermal efficiency of a bi-fuel hydrogen/gasoline engine, at several engine speeds and loads. Results on hydrogen are compared to results on gasoline. Hydrogen offers the possibility of a more flexible load control strategy. Where possible, results are compared between the wide open throttle, lean burn strategy and the throttled stoichiometric strategy.
\end{abstract}

Keywords: internal combustion engine; hydrogen; gasoline; bi-fuel; efficiency; emissions

\section{Nomenclature}

Greek Symbols

$\lambda \quad$ air to fuel equivalence ratio

Abbreviations

bmep brake mean effective pressure

BTDC before top dead center

BTE brake thermal efficiency

CVVT continuously variable valve timing

DI direct injection

EGR exhaust gas recirculation

ICE internal combustion engine

IT ignition timing

IVO intake valve opening time

MAF mass air flow

MBT minimum spark advance for best torque

PFI port fuel injection

TDC top dead center

TP throttle position

TWC three way catalyst

WOT wide open throttle 


\section{Introduction}

Greenhouse gas emission by the transport sector is a hot topic these days. There is a strong drive towards legislation limiting the fleet average $\mathrm{CO}_{2}$ emissions [1]. The use of hydrogen as an energy carrier is one option with the potential of lowering $\mathrm{CO}_{2}$ emissions investigated by the vehicle manufacturers. However, affordable fuel cell vehicles seem to be a long way off [2]. An interesting alternative is using hydrogen in internal combustion engines (ICEs). Next to being less expensive, hydrogen-fueled ICEs offer a number of other benefits of which the most practical one is the ability to run in bi-fuel or flex-fuel operation. These benefits, and experimental research on hydrogen-fueled ICEs is reviewed by the authors elsewhere [3].

Hydrogen is a very versatile engine fuel when it comes to load control. The high flame speeds of hydrogen mixtures and its wide flammability limits permit very lean operation and substantial dilution. The engine efficiency and the emission of oxides of nitrogen $\left(\mathrm{NO}_{\mathrm{x}}\right)$ are the two main parameters used to decide the load control strategy. Constant equivalence ratio throttled operation has been used but mainly for demonstration purposes $[4,5,6]$, as it is fairly easy to run a lean burn throttled hydrogen engine (when accepting the severe power output penalty). Where possible, wide open throttle (WOT) operation is used to take advantage of the associated increase in engine efficiency [7, 8, 9], regulating load with mixture richness (qualitative control) instead of volumetric efficiency (quantitative control) and thus avoiding pumping losses. Limitations to WOT operation are due to misfires, unburned hydrogen and decreased stability at very low load (e.g. idling) and $\mathrm{NO}_{\mathrm{X}}$ emissions at medium to full load. Thus, throttling is used at very low loads to increase combustion stability and decrease unburned hydrogen emissions $[6,10,11,12,13]$. Moreover, this increases the efficiency at these (ultralean) conditions: the efficiency gain through decrease of unburned hydrogen emissions (and possibly also by a shorter, more efficient combustion) offsets the efficiency loss by throttling. The engine efficiency using throttled or WOT operation is compared in refs. [6, 14], the lean limit at which throttling is introduced is engine dependent and ranges from $\lambda=3[11]$ to $\lambda=4[6,10]$.

For higher loads, flame temperatures quickly exceed the $\mathrm{NO}_{\mathrm{X}}$ generation limit. This results in a $\mathrm{NO}_{\mathrm{X}}$ limit to WOT operation. One could restrict the mixture richness and use sufficiently lean mixtures to stay below a 10 or $100 \mathrm{ppm} \mathrm{NO}_{\mathrm{X}}$ limit, but this implies a large decrease in maximum power output. Alternatively, the engine can be throttled above this limit, using stoichiometric mixtures and thus enabling the use of a conventional three way catalyst for $\mathrm{NO}_{\mathrm{X}}$ reduction [10]. The mixture richness is then set slightly rich of stoichiometric so that some unburned $\mathrm{H}_{2}$ is present in the exhaust which is a very effective reducing agent for $\mathrm{NO}_{\mathrm{X}}$ [15]. However, this strategy implies a decrease in engine efficiency. Yet another strategy is the use of EGR to control load: using stoichiometric mixtures but instead of throttling, recycling exhaust gas in a proportion dependent on the power demand $[14,16,17]$. This gives a better efficiency compared to throttling. EGR is also a means to allow backfire-free operation at stoichiometric mixtures, enabling a higher power output if $\mathrm{NO}_{\mathrm{X}}$ emissions are a boundary condition $[16,18]$. Water injection can also be used to decrease $\mathrm{NO}_{\mathrm{x}}$ emissions from the richer mixtures [11, 19], and is more effective than EGR [4] but is mostly considered impractical. Work has been reported using a 'dual fluid injector' for DI [18], which injects hydrogen and liquid water directly in the combustion chamber, for decreased $\mathrm{NO}_{\mathrm{X}}$. 
Finding means to maximize engine efficiency is very important for $\mathrm{H}_{2}$ ICEs considering the $\mathrm{H}_{2}$ on-board storage challenge. Quantifying the efficiency of $\mathrm{H}_{2}$ ICEs is useful for assessing the possible vehicle range. Several papers have reported efficiencies of engines operated on hydrogen. Ford [6,14,20] published figures obtained on a dedicated hydrogen engine, where (among others) the compression ratio was optimized to take advantage of the high auto-ignition temperature of hydrogen. Tang et al. [6] mapped the brake specific fuel consumption, both for a constant equivalence ratio, throttled strategy as a wide open throttle strategy (regulating load with mixture richness). Brake and indicated thermal efficiencies were shown, as a function of equivalence ratio, for different compression ratios and engine speeds. The maximum indicated thermal efficiency was $52 \%$, which was for a $\lambda=3.3$ and $5000 \mathrm{rpm}$ condition. The maximum brake thermal efficiency peaked at $38 \%$, around $\lambda=2$ and 2000 rpm. Natkin et al. [14] reported brake thermal efficiencies of a comparable engine, with the addition of a supercharger to increase the power output. The supercharged engine reached a maximum indicated thermal efficiency of $50 \%$ and a maximum brake thermal efficiency of $37 \%$. The authors also report a relative increase of 15 to $20 \%$ in brake thermal efficiency at the lower loads when using the equivalence ratio to control load (WOT, qualitative control strategy) rather than throttling (quantitative control strategy). Finally, in a joint publication with Westport Innovations and Pacific Northwest National Laboratory, Ford report an estimated peak brake thermal efficiency of $45 \%$ obtained on a single cylinder DI engine [20].

BMW [10,15,21,22] reported efficiency figures for the different load control strategies. Eichlseder et al. [22] provide a limited comparison of the efficiency of hydrogen versus gasoline operation. Next to the properties of hydrogen that are beneficial for the efficiency, see above, it is also noted that higher wall heat losses are to be expected for hydrogen, which has a negative effect on the efficiency. Berckmüller et al. [10] showed an indicated thermal efficiency map for a port fuel injected engine, including the wide open throttle strategy, throttled stoichiometric and supercharged stoichiometric strategies. Indicated thermal efficiencies reached $40 \%$ at low load and 32\% at high load. They also mapped the stoichiometric+EGR strategy as an alternative to the throttled stoichiometric approach, which resulted in increased efficiency (roughly 2 percentage points). Rottengruber et al. [15] plotted a similar map, but using direct injection at the higher loads, which enabled higher efficiencies compared to the PFI supercharged approach.

Several other papers also report efficiencies, as a function of equivalence ratio and ignition timing [19], as a function of the injection timing and intake manifold geometry for a PFI engine [23], as a function of the injection timing and injector location for a DI engine [24], etc.

All of these papers show efficiency figures above those typically reached with gasoline, but no direct comparisons are included. The BMW Hydrogen 7 semi-production vehicle [21] is a bi-fuel vehicle but unfortunately no efficiency figures were stated in the paper. For the mono-fuel derivative, fuel consumption figures are reported by Wallner et al. [25], but those are for the vehicle so include transmission losses etc.

The authors found only one report of efficiency measurements on the same engine, on gasoline as well as on hydrogen [26], but this was for a carbureted engine. The present paper thus aims to report some efficiency figures, on a modern engine, which can be directly compared. The easiest way to introduce hydrogen ICEs is by converting a gasoline engine to bi-fuel operation, by mounting a hydrogen fuel system and gas injectors. Starting 
from a gasoline engine implies port fuel injection (PFI) of the hydrogen. Therefore, this paper concentrates on hydrogen PFI engines, although dedicated hydrogen engines would benefit greatly from direct injection $[3,20]$.

\section{Experimental set-up}

A Volvo four cylinder sixteen valve gasoline engine with a total swept volume of $1783 \mathrm{cc}$ and a compression ratio of 10.3:1 was converted to bi-fuel operation by mounting an additional fuel rail supplying gaseous fuel (in this case, hydrogen) to 8 Teleflex GSI gas injectors ( 2 per cylinder), mounted on the intake manifold. The intake manifold was modified to avoid any damage if backfire would occur during the hydrogen measurements: a Ttype branch pipe was mounted on the intake manifold with the 'straight ahead' branch closed by a foam plug and the other branch leading to the air filter - mass air flow (MAF) sensor - throttle valve assembly, see Fig. 1. Any pressure rise in the intake manifold due to the occurrence of backfire results in the foam plug being blown out instead of damaging other components such as the MAF sensor.

The engine has continuously variable valve timing (CVVT) on the intake camshaft, allowing up to 40 degrees crank angle $\left({ }^{\circ} \mathrm{ca}\right)$ advance of the intake valve opening and closing time. A MoTeC M800 engine control unit is used to control ignition timing, start of injection, injection duration and intake valve timing. Cylinder pressure measurements were possible using a spark plug pressure sensor, a piezo-electric Kistler type 6117BFG16. A piezo-resistive Kistler type 4075A20 sensor placed in the intake manifold close to the inlet valves was used for pegging the cylinder pressure. The crank angle was recorded using a Kistler crank angle encoder type 2613B1.

Initial measurements were at a fixed engine speed of $1500 \mathrm{rpm}$, due to restrictions in hydrogen storage at that time. Later on, a larger storage permitted higher engine speeds. The resulting large changes in hydrogen flow (low load - low speed, to high load - high speed) led to difficulty in keeping the hydrogen injection pressure constant, with manual corrections being necessary. As this is cumbersome and introduces the possibility of erroneous measurements, an automatic pressure regulator was installed. The pressure regulator that was chosen for this was a Fairchild type $4500 \mathrm{~A}$, using laboratory pressurized air to regulate the pressure so that it is independent of the flow rate. Due to the operating principle of this regulator, it is possible that some hydrogen has to be blown off to avoid a pressure increase downstream (e.g. going from a high load high speed point to idling). A tube was connected to this blow off opening and led to a tapered roof above the engine test bench, where a Buveco Bucom ST600EX hydrogen sensor was installed at the highest point.

The exhaust gas components $\mathrm{O}_{2}, \mathrm{CO}, \mathrm{CO}_{2}, \mathrm{NO}, \mathrm{NO}_{\mathrm{X}}$ and $\mathrm{H}_{2}$ are measured $\left(\mathrm{O}_{2}\right.$ : Maihak Oxor-P S710, paramagnetic; $\mathrm{CO}-\mathrm{CO}_{2}-\mathrm{NO}-\mathrm{NO}_{2}$ : Maihak Multor 610, non-dispersive infra red; $\mathrm{H}_{2}$ : Maihak Thermor 615, thermal conductivity). A direct reading of the air to fuel equivalence ratio $\lambda$ is given by a Bosch wide band sensor and digital air/fuel ratio meter with calibrations for hydrogen and gasoline.

\section{Results}

First, the $\mathrm{NO}_{\mathrm{X}}$ threshold equivalence ratio was determined for the test engine. Figure 2 shows the $\mathrm{NO}_{\mathrm{X}}$ emissions as a function of air to fuel equivalence ratio, for wide open throttle operation. $\mathrm{NO}_{\mathrm{X}}$ emissions can be seen to rise very rapidly once the equivalence ratio is lower than 2 . For practical purposes, and considering the steepness of the $\mathrm{NO}_{\mathrm{X}}$ versus $\lambda$ curve, a threshold of $100 \mathrm{ppm}$ was chosen, consistent with other work [15]. Next, a single 
operating point was chosen to illustrate the distinct features of hydrogen compared to gasoline. For this, the power output on hydrogen at $1500 \mathrm{rpm}$, WOT and the $\mathrm{NO}_{\mathrm{X}}$ threshold equivalence ratio for this engine $(\lambda=2)$, was determined $(9.1 \mathrm{~kW}$, corresponding to a bmep of $4.1 \mathrm{bar}$ ). This would correspond to a low load, steady cruise in a high gear. Next, the same combination of engine speed and power output was set using throttling and stoichiometric operation, both on hydrogen and on gasoline. The optimal intake cam advance was used (for differences between gasoline and hydrogen, see [27]). Table 1 shows the engine settings and resulting brake thermal efficiency (BTE) for the three points: hydrogen WOT, hydrogen stoichiometric and throttled, gasoline stoichiometric and throttled. Figures 3 to 5 show the corresponding diagrams of cylinder pressure versus volume, in logarithmic coordinates.

It is clear that the wide open throttle strategy should be used wherever possible because of the high efficiencies, as pumping losses are quasi zero, see Fig. 3. Using the stoichiometric + throttling approach still leads to substantially higher efficiencies for hydrogen compared to gasoline (at this load). The high burning velocity and corresponding (almost) constant volume combustion (see Fig. 4) explains this partly. The lower volumetric energy density of the hydrogen-air mixture (resulting from the low density of hydrogen, but partially compensated by the high heating value of hydrogen) also means that a larger throttle opening (TP) is necessary for the same power output, decreasing pumping losses, see Fig. 4 versus Fig. 5 and Table 1. Although the difference in throttle opening is fairly small, the air flow is substantially lower in the case of hydrogen, as compared to gasoline. Consequently, the pumping work is lower.

Next, the efficiencies while using gasoline and hydrogen were compared at different torque settings $(20,40$ and $80 \mathrm{Nm}$ - equivalent to 1.41, 2.82 and 5.64 bar bmep) and different engine speeds since the influence of the gas dynamics increases with an increasing engine speed. For hydrogen, high torque outputs were limited by the appearance of backfire. At each point, MBT-timing and a fixed Intake Valve Opening (IVO) advance of $4^{\circ} \mathrm{ca}$ BTDC was used. The influence of the IVO advance on the brake torque is fairly limited (up to $3 \%$ torque rise), this justifies using a fixed IVO advance. Initial hydrogen measurements were carried out at WOT. The highest BTE is expected for this strategy, as explained above: this is mainly caused by the lower pressure losses in the intake system as a consequence of the absence of throttle losses. Next, measurements were taken for a throttle position of $50 \%$ to be able to evaluate the influence of the increasing pressure losses. As a consequence of throttling, the mixture had to be set richer for the same power output. For TP $=50 \%$ it was not possible to run the engine at $80 \mathrm{Nm}$ since the mixture became too rich with backfire as a consequence.

Figures 6 and 7 show the brake thermal efficiencies as a function of engine speed, for fixed torque outputs of 20 and $40 \mathrm{Nm}$ respectively. Three BTE curves are shown, one is for gasoline (throttled, stoichiometric) operation for which the corresponding throttle position is shown in the middle part of the graph. The other two are for hydrogen with wide open throttle and with a $\mathrm{TP}=50 \%$ respectively, for these two cases the corresponding equivalence ratios are given in the top part of the graph.

From Figs. 6 and 7 it is clear that at these low loads, the brake thermal efficiency on hydrogen is (much) higher than on gasoline, the hydrogen BTEs are 40 to $60 \%$ higher relative to the gasoline BTEs. This difference is due to the absence of throttling losses (or much lower throttle losses in the $\mathrm{H} 2 \mathrm{TP}=50 \%$ case) and the lean mixtures 
for hydrogen. The higher burning velocity of hydrogen is also a contributing factor, as this leads to a more isochoric combustion (see also Figs. 4 and 5). The influence of this factor can be seen directly in Fig. 7 for the $4500 \mathrm{rpm}$ point: the throttle position for gasoline is about $50 \%$ there, so the efficiency can be compared to the $\mathrm{H}_{2}$ $\mathrm{TP}=50 \%$ case. The BTE on hydrogen for this condition is about $18 \%$ higher relative to gasoline. This difference is not entirely down to a difference in burning velocity however: as hydrogen displaces more air due to its low density, throttling losses are lower even though the throttle position is identical, as the lower air flow results in lower flow losses.

The gasoline BTE can be seen to be relatively insensitive to the engine speed. On the one hand, the increasing air flow with engine speed causes higher flow losses but on the other hand, as seen from the TP curve, the throttle opening has to be increased with engine speed to keep the torque output constant, which decreases the throttling losses. Both effects seem to cancel each other out.

For hydrogen, the BTE decreases with engine speed, although the decrease is less pronounced for the WOT case. Two effects explain this behavior: first, due to the lean burn operation and large throttle openings, the air flow is much higher in the hydrogen case than for gasoline. This leads to higher flow losses in the intake manifold. To keep the torque output fixed, this means more hydrogen needs to be injected at higher engine speeds to compensate for these higher losses, with a reduced efficiency as a consequence. For the throttled case, the flow losses include pumping losses so for this case, the BTE is lower and decreases more strongly with engine speed. The increasing hydrogen flow can be seen in the $\lambda$ curves for the throttled case in Figs. 6 and 7, which show a decreasing air to fuel equivalence ratio with increasing engine speed. For the WOT case the air to fuel equivalence ratio is more or less constant: the air flow also increases due to an increasing volumetric efficiency. The increasing hydrogen flow results in a second effect, of an increasing air displacement (i.e. air flow decreases) and thus lower flow losses. However, the net air flow increases with engine speed so the intake flow losses increase with engine speed.

For the lowest engine speeds at the lowest load (Fig. 6) the BTE for the $\mathrm{H}_{2} \mathrm{TP}=50 \%$ case can be seen to be slightly higher than for the WOT case. Here, the increased turbulence due to throttling is beneficial for the combustion stability of the ultra lean mixtures (see the $\lambda$ curves).

In Figs. 6 and 7, the air to fuel equivalence ratio for the WOT case is always higher than 2, as a result $\mathrm{NO}_{\mathrm{X}}$ emissions are very low. All these points can thus be part of a practical load control strategy. For the TP $=50 \%$ points, the equivalence ratios do drop under 2, with corresponding high $\mathrm{NO}_{\mathrm{X}}$ emissions, in an oxygen-rich exhaust. Thus, these cannot be used in practice. However, as the BTE of this strategy is lower than in the WOT case this is not an issue.

With a throttle position at $50 \%$, it was not possible to reach $80 \mathrm{Nm}$ with hydrogen. Thus Fig. 8 , which shows the brake thermal efficiencies as a function of engine speed, for a fixed torque output of $80 \mathrm{Nm}$, does not contain a $\mathrm{TP}=50 \%$ curve. Instead, for the throttled hydrogen case, the TP was set so that a stoichiometric mixture was 
obtained. In that case, $\mathrm{NO}_{\mathrm{X}}$ emissions can be treated in a TWC (three way catalyst) with high conversion efficiencies.

First, comparing Figs. 6, 7 and 8, the efficiencies of both gasoline and hydrogen can be seen to increase as the delivered torque increases. The explanation differs slightly for gasoline and hydrogen. In the three cases, as a result of the increasing torque, the mechanical efficiency increases strongly. For gasoline, the flow losses across the throttle valve increase because of the larger flow, although this is slightly compensated by a larger TP. The increase in mechanical efficiency is clearly the dominating effect. In the case of hydrogen, the flow losses decrease because of a smaller air flow since more air is displaced by hydrogen as a result of the richer mixture. This also leads to a decreased influence of engine speed on the hydrogen BTEs: from the figures it can be seen that as the load increases, the BTE decreases less strongly with engine speed.

Secondly, Fig. 8 shows that hydrogen WOT measurements at $80 \mathrm{Nm}$ (for all engine speeds) have an air to fuel equivalence ratio between 1 and 2. This is below the 'threshold' equivalence ratio, taking a $\mathrm{NO}_{\mathrm{X}}$ emission of 100 ppm as the threshold. As explained above, for an equivalence ratio between 1 and 2 it is impossible to reduce the $\mathrm{NO}_{\mathrm{X}}$ emissions with sufficient efficiency using a TWC since the exhaust oxygen concentration is too high. As a consequence, these points are useless for an automotive application. The efficiency penalty caused by the $\mathrm{NO}_{\mathrm{X}}$ boundary condition can be seen by comparing the $\mathrm{H}_{2}$ WOT BTE curve to the $\mathrm{H}_{2} \lambda=1$ BTE curve, showing a relative decrease in BTE of 5 to $10 \%$.

Finally, for the $80 \mathrm{Nm}$ case, the BTE on hydrogen is still higher than on gasoline, but the difference is lower than for the lower loads (between 10 and 30\% relatively, comparing gasoline to the $\mathrm{H}_{2} \lambda=1$ case).

In Fig. 8 there are no values given for the $\mathrm{H}_{2} \lambda=1$ case at $4500 \mathrm{rpm}$. This condition could not be set because of backfire occurrence.

\section{Conclusion}

If the efficiency results reported in the references, discussed in the introduction, are combined with the present experimental results, it is safe to say that the brake thermal efficiency of a hydrogen engine exceeds that of a gasoline engine over the entire speed and load range. The present results quantify this efficiency increase.

$\mathrm{NO}_{\mathrm{X}}$ emissions control incurs an efficiency penalty at the higher loads, although hydrogen keeps its efficiency advantage over gasoline. At low loads, important in drive cycles as well as for everyday driving, the efficiency gains of hydrogen compared to gasoline are particularly high (up to 60\% relative increase of the BTE). If this is the case for a gasoline engine that was converted to allow operation on hydrogen, with a resulting compromise for the BTE on hydrogen, one can expect the differences in BTE to be even higher for a dedicated $\mathrm{H}_{2} \mathrm{ICE}$.

\section{References}

[1]. Leading by $\mathrm{CO}_{2}$ example. Editorial, Automotive Engineering International, April 2007.

[2]. Fuel Cells. Cover story, Engine Technology International, June 2007. 
[3]. Verhelst S., Verstraeten S., Sierens R. 'A critical review of experimental research on hydrogen fueled SI engines'. SAE technical paper nr 2006-01-0430. Also in SAE 2006 Transactions, Journal of Engines, pp264-274.

[4]. Davidson D., Fairlie M., and Stuart A.E. Development of a hydrogen-fueled farm tractor. Int. J. Hydrogen Energy, 11:39-42, 1986.

[5]. Olavson L.G., Baker N.R., Lynch F.E., and Meija L.C. Hydrogen fuel for underground mining machinery. SAE, paper nr 840233, 1984.

[6]. Tang X., Kabat D.M., Natkin R.J., Stockhausen W.F., and Heffel J. Ford P2000 hydrogen engine dynamometer development. SAE, paper nr 2002-01-0242, 2002.

[7]. Heffel J.W., Johnson D.C., and Shelby C. Hydrogen powered Shelby Cobra: vehicle conversion. SAE, paper nr 2001-01-2530, 2001.

[8]. Smith J.R., Aceves S., and Van Blarigan P. Series hybrid vehicle and optimized hydrogen engine design. SAE, paper nr 951955, 1995.

[9]. Verhelst S. and Sierens R. Aspects concerning the optimisation of a hydrogen fueled engine. Int. J. Hydrogen Energy, 26:981-5, 2001.

[10]. Berckmüller M., Rottengruber H., Eder A., Brehm N., Elsässer G., Müller-Alander G., and Schwarz C. Potentials of a charged SI-hydrogen engine. SAE, paper nr 2003-01-3210, 2003.

[11]. Project Coordinator Motor Vehicles and Road Transport, TÜV Rheinland e.V. for the Federal Ministry for Research and Technology. Alternative energy sources for road transport - hydrogen drive test. Technical report, TÜV Rheinland, 1990.

[12]. Jing-Ding L., Ying-Qing L., and Tian-Shen D. Improvement on the combustion of a hydrogen fueled engine. Int. J. Hydrogen Energy, 11:661-668, 1986.

[13]. Guo L.S., Lu H.B., and Li J.D. A hydrogen injection system with solenoid valves for a four cylinder hydrogen-fueled engine. Int. J. Hydrogen Energy, 24:377-382, 1999.

[14]. Natkin R.J., Tang X., Boyer B., Oltmans B., Denlinger A., and Heffel J.W. Hydrogen IC engine boosting performance and NOx study. SAE, paper nr 2003-01-0631, 2003.

[15]. Rottengruber H., Berckmüller M., Elsässer G., Brehm N., and Schwarz C. A high-efficient combustion concept for direct injection hydrogen internal combustion engine. 15th World Hydrogen Energy Conference, paper nr 28J-01, Yokohama, Japan, 2004.

[16]. Heffel J.W. $\mathrm{NO}_{\mathrm{X}}$ emission reduction in a hydrogen fueled internal combustion engine at $3000 \mathrm{rpm}$ using exhaust gas recirculation. Int. J. Hydrogen Energy, 28:1285-1292, 2003.

[17]. Verhelst S. and Sierens R. Combustion Studies for PFI Hydrogen IC Engines. SAE, paper nr 2007-013610, 2007.

[18]. Bleechmore C. and Brewster S. Dilution strategies for load and $\mathrm{NO}_{\mathrm{X}}$ management in a hydrogen fueled direct injection engine. SAE, paper nr 2007-01-4097, 2007.

[19]. Subramanian V., Mallikanjuna J.M., and Ramesh A. Effect of water injection and spark timing on the nitric oxide emission and combustion parameters of a hydrogen fueled spark ignition engine. Int. J. Hydrogen Energy, 32:1159-1173, 2007. 
[20]. Welch A., Mumford D., Munshi S., Holsbery J., Boyer D. Younhins M., and Jung H. Challenges in developing hydrogen direct injection technology for internal combustion engines. SAE, paper nr 2008-012379, 2008.

[21]. Kiesgen G., Klüting M., Bock C., and Fischer H. The new 12-cylinder hydrogen engine in the 7 series: the H2 ICE age has begun. SAE, paper nr 2006-01-0431, 2006.

[22]. Eichlseder H., Wallner T., Freymann R. and Ringler J. The potential of hydrogen internal combustion engines in a future mobility scenario. SAE, paper nr 2003-021-2267, 2003

[23]. Sierens R. and Verhelst S. Influence of the injection parameters on the efficiency and power output of a hydrogen fueled engine. Transactions of the ASME: J. Eng. Gas Turbines and Power, 125:444-449, 2003.

[24]. Wallner T., Nande A.M., and Naber J. Evaluation of injector location and nozzle design in a directinjection hydrogen research engine. SAE, paper nr 2008-01-1785, 2005.

[25]. Wallner T., Lohse-Busch H., Gurski S., Duoba M., and Thiel W. Fuel economy and emissions evaluation of BMW Hydrogen 7 mono-fuel demonstration vehicles. Int. J. Hydrogen Energy (2008), doi:10.1016/j.ijhydene.2008.08.067

[26]. Kahraman E., Cihangir Orcanli S., and Orerdem B. An experimental study on performance and emission chraracteristics of a hydrogen fueled spark ignition engine. Int. J. Hydrogen energy, 32: 2066-2077, 2007. But this was done on a carbureted engine.

[27]. Verhelst S., De Landtsheere J., De Smet F., Billiouw C., Trenson A., Sierens R. Effects of Supercharging, EGR and Variable Valve Timing on Power and Emissions of Hydrogen Internal Combustion Engines. SAE, paper 2008-01-1033, 2008. 


\section{Figure and table captions}

\section{Figure captions}

Figure 1. Modified intake of four cylinder bi-fuel engine

Figure 2. $\mathrm{NO}_{\mathrm{X}}$ emissions as a function of air to fuel equivalence ratio, for wide open throttle operation (1500 rpm)

Figure 3. Cylinder pressure versus cylinder volume, fuel $=$ hydrogen, WOT, $\lambda=2$

Figure 4. Cylinder pressure versus cylinder volume, fuel = hydrogen, throttled $(\mathrm{TP}=30 \%), \lambda=1$

Figure 5. Cylinder pressure versus cylinder volume, fuel $=$ gasoline, throttled $(\mathrm{TP}=28.5 \%), \lambda=1$

Figure 6. Brake thermal efficiency and respective throttle position or equivalence ratio as a function of engine speed, for a fixed brake torque of $20 \mathrm{Nm}$.

Figure 7. Brake thermal efficiency and respective throttle position or equivalence ratio as a function of engine speed, for a fixed brake torque of $40 \mathrm{Nm}$.

Figure 8: Brake thermal efficiency and respective throttle position or equivalence ratio as a function of engine speed, for a fixed brake torque of $80 \mathrm{Nm}$.

\section{Table captions}

Table 1. Efficiency comparison of hydrogen versus gasoline at $1500 \mathrm{rpm}$ and an effective power output of 9.1 $\mathrm{kW}$ 


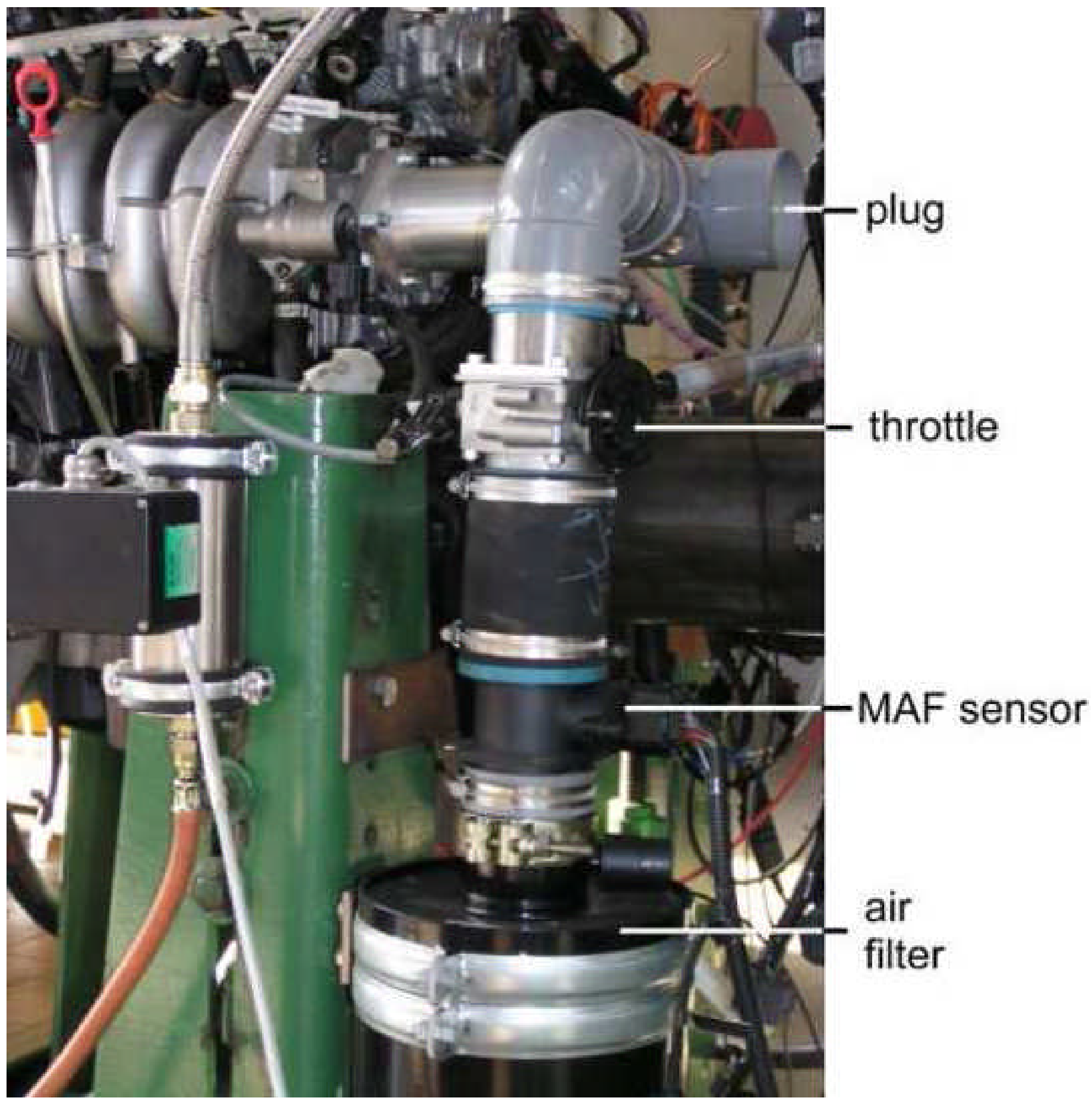




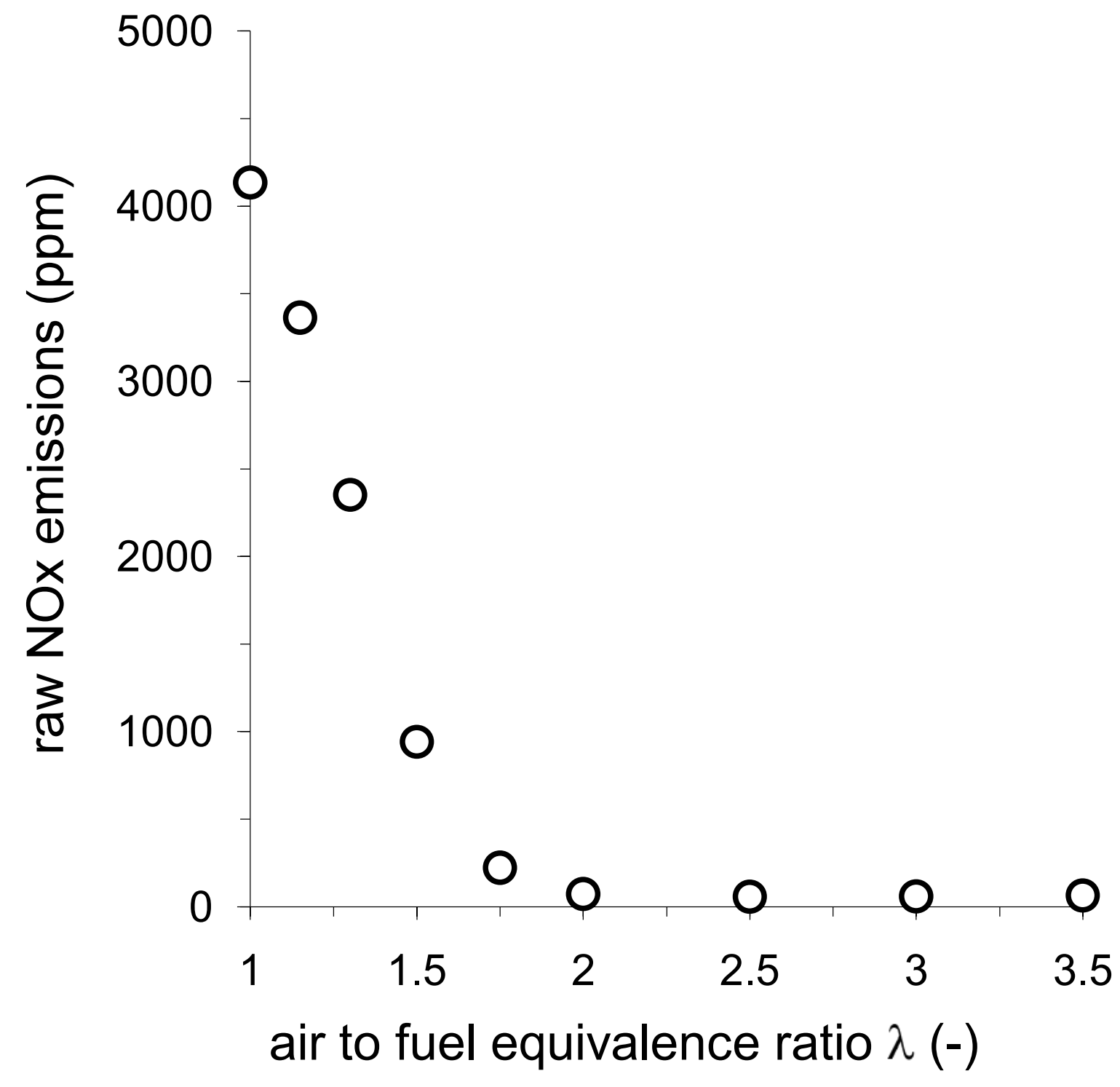




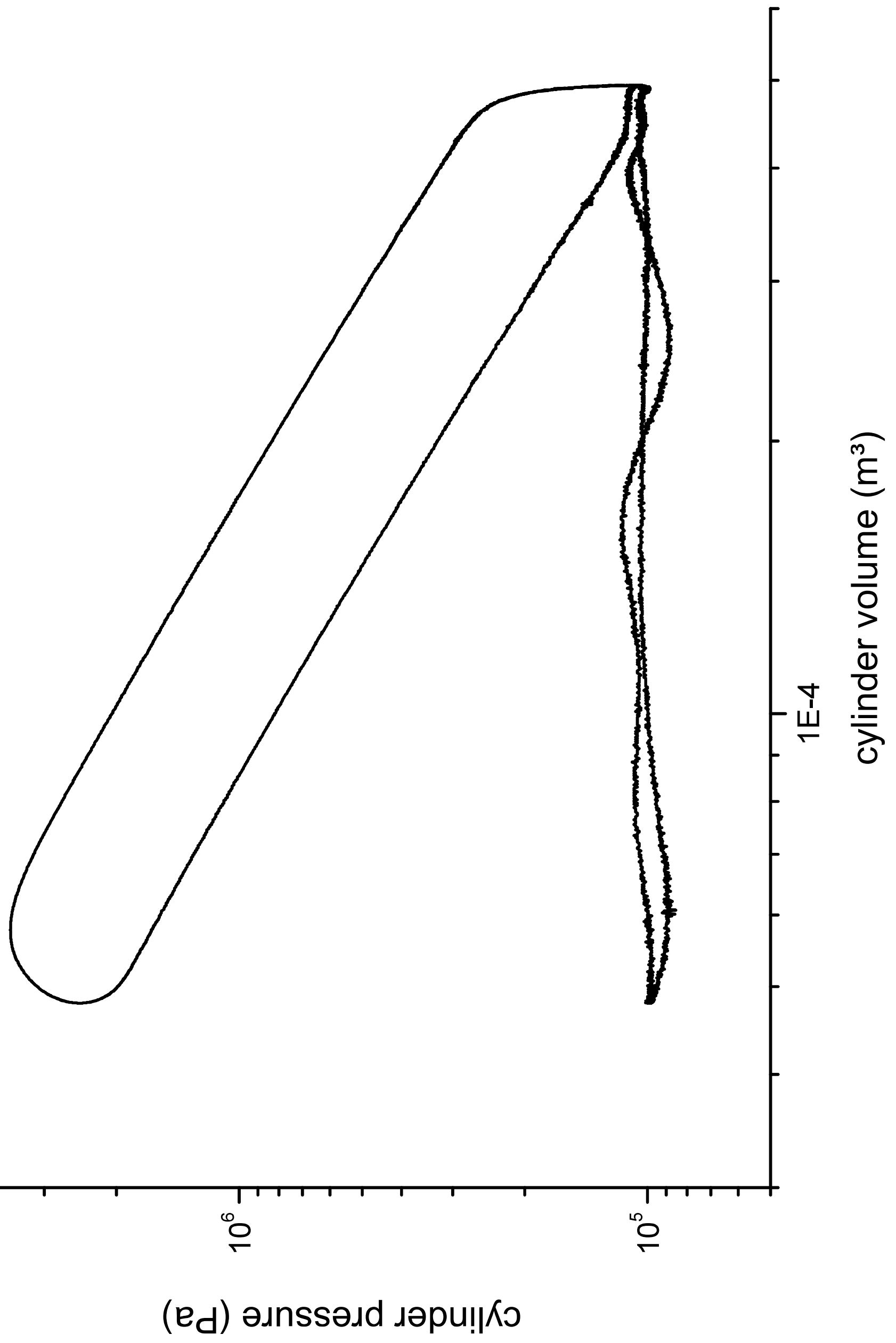




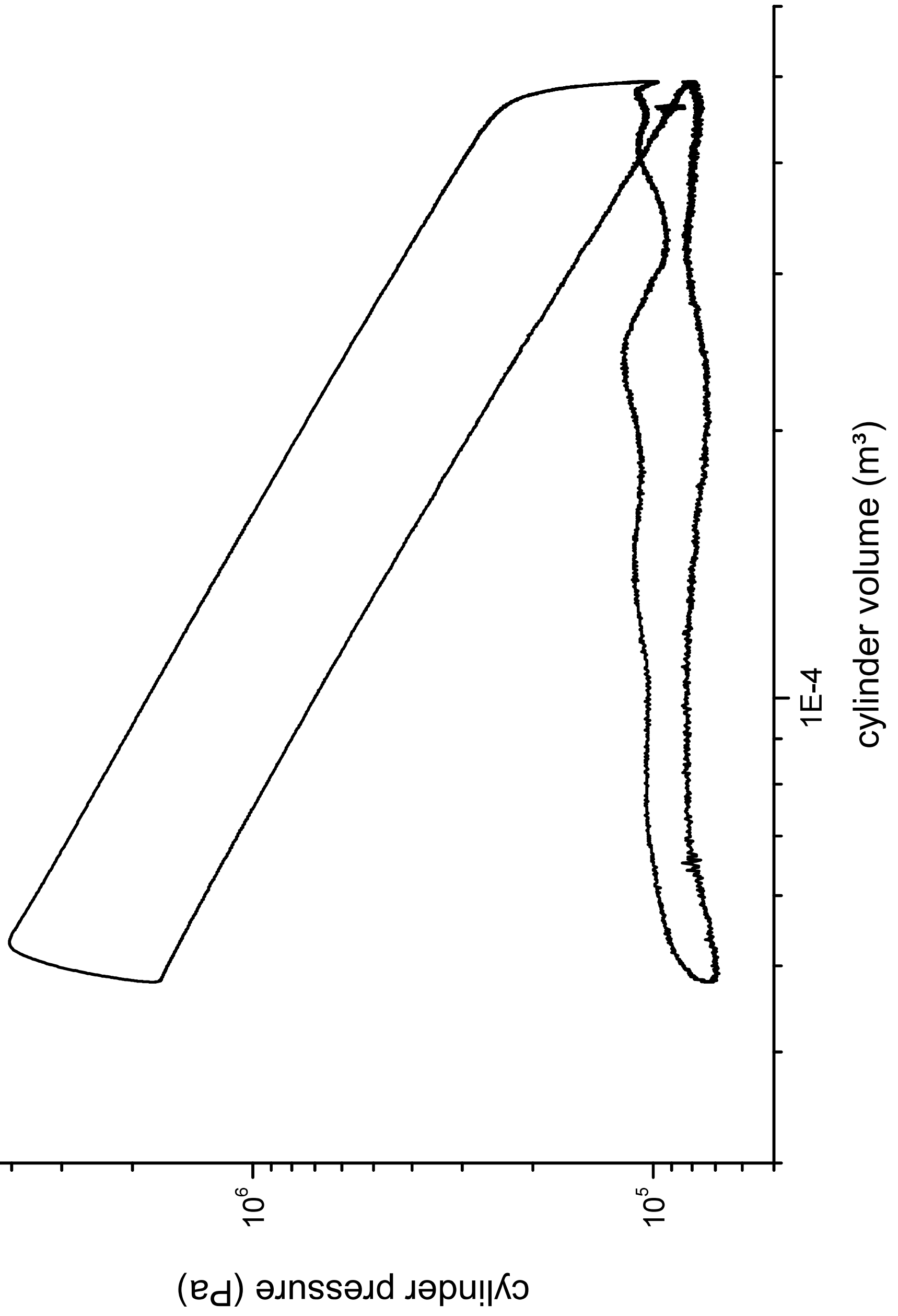




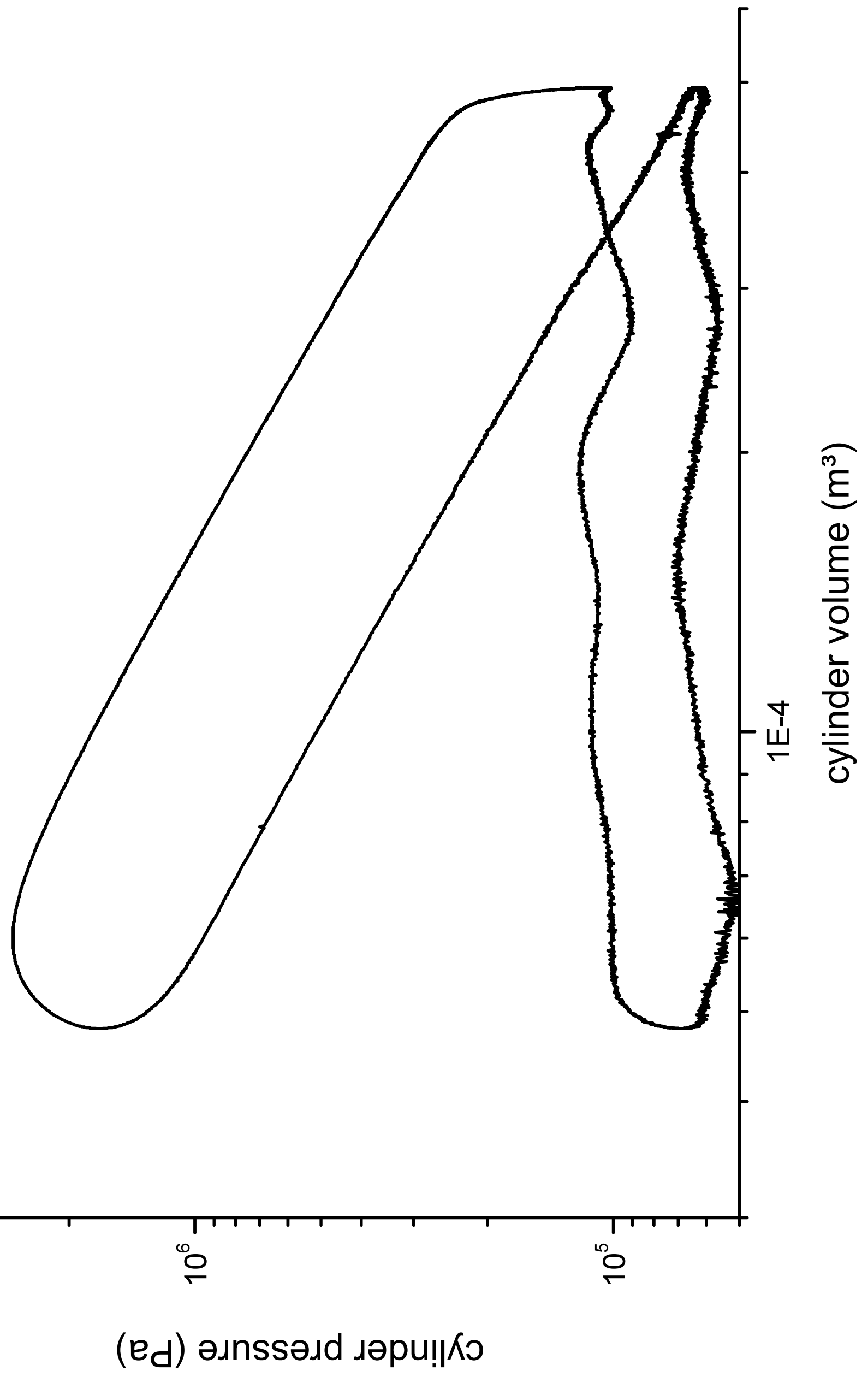




\section{Figure6}

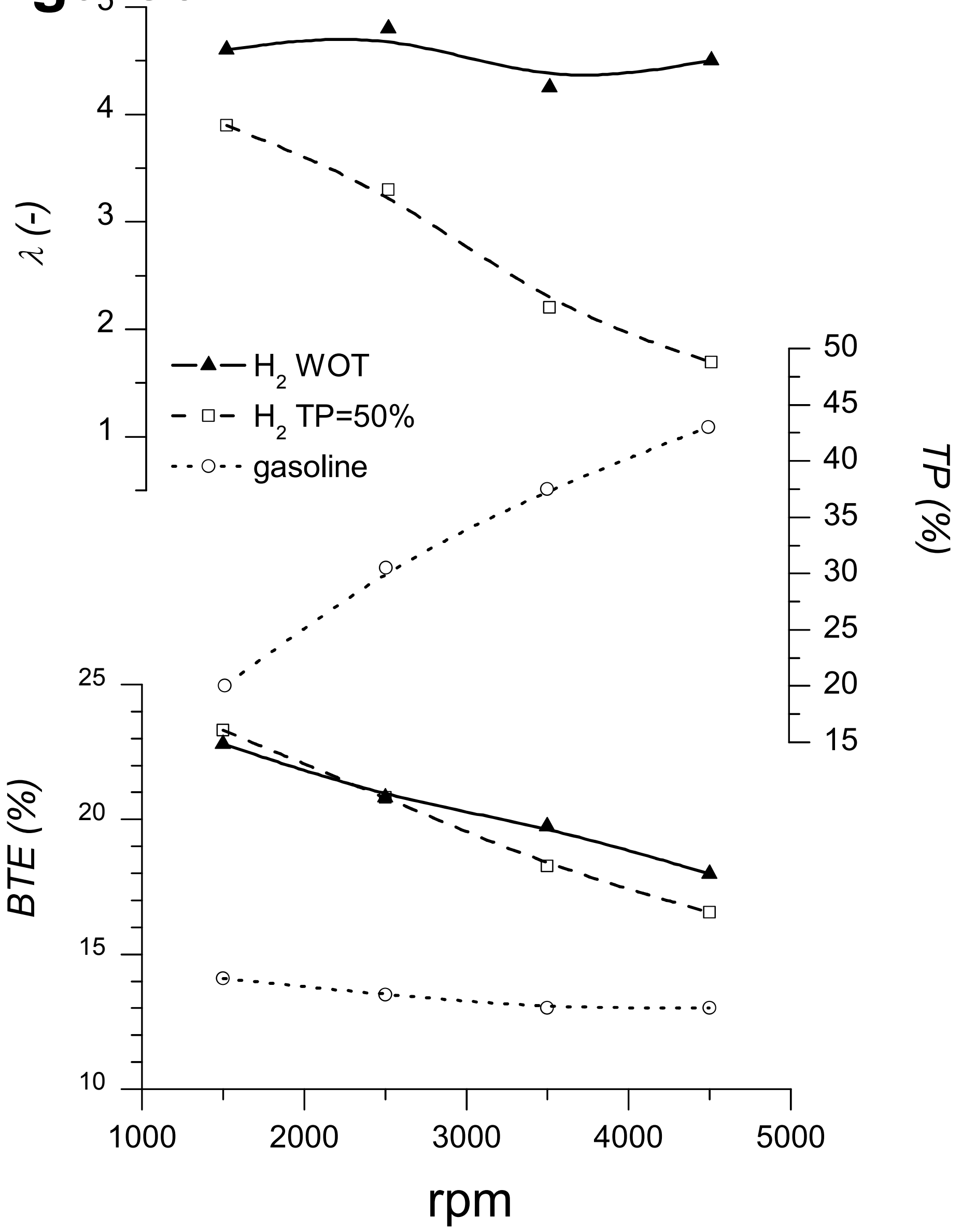


Figure7

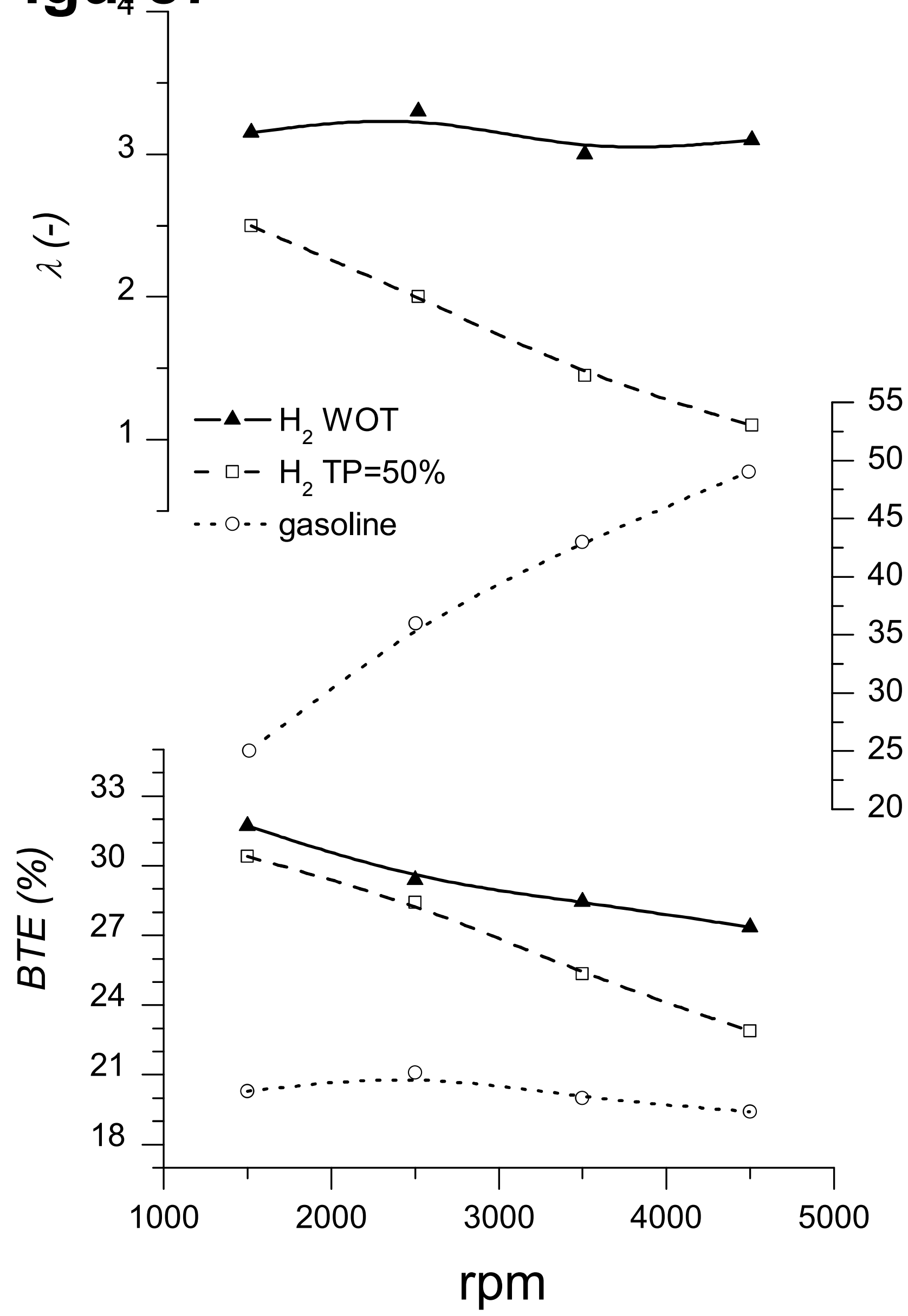




\section{Figures}

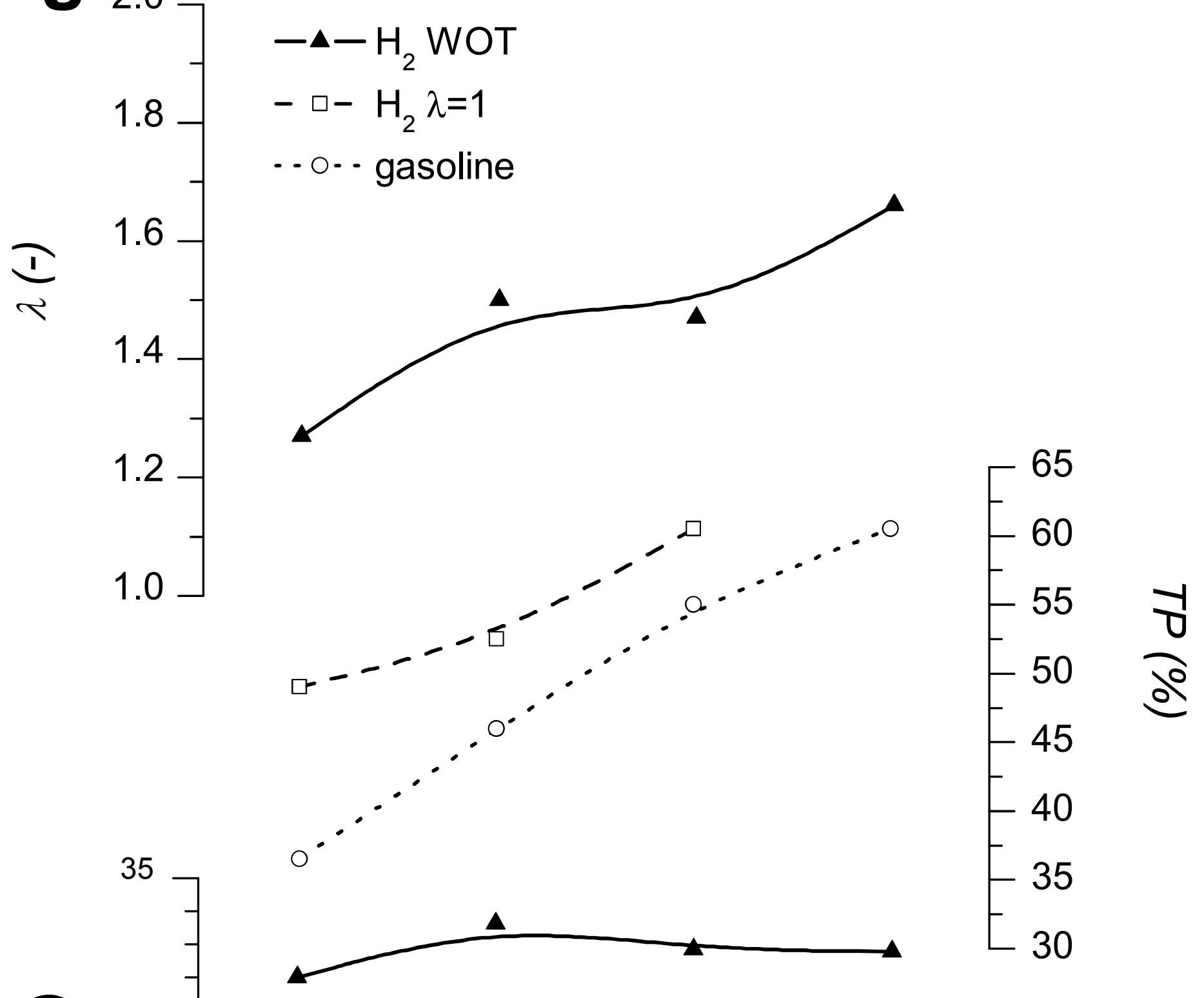

$\frac{\widehat{d}}{\stackrel{w}{\circ}}$

30 f

20 


\begin{tabular}{r|ccc} 
& Hydrogen & Hydrogen & Gasoline \\
\hline$\lambda$ & 2 & 1 & 1 \\
TP (\%) & 100 & 30 & 28.5 \\
IT ( $\left.{ }^{\circ} \mathrm{ca} \mathrm{BTDC}\right)$ & 10 & -1 & 23 \\
IVO adv. ( $\left.{ }^{\circ} \mathrm{ca}\right)$ & 0 & 40 & 28 \\
BTE (\%) & 34.2 & 28.2 & 20.8
\end{tabular}

Table 1. Efficiency comparison of hydrogen versus gasoline at $1500 \mathrm{rpm}$ and an effective power output of 9.1 $\mathrm{kW}$ 